\title{
TEMPO DE ROUPA NOVA: \\ BELEZA E TRANSFORMAÇÃO NO TAMBOR DA MATA DE CODÓ (MA)
}

\author{
Martina Ahlert ${ }^{1}$
}

A noite da "roupa nova" é a mais importante dos dias de festejo nas tendas das religiões afro-brasileiras de Codó, cidade localizada na região leste do Maranhão. O festejo de maior destaque de cada tenda - tenha ele duração de nove ou de apenas uma noite - compreende a feitura de uma roupa então inédita, a ser orgulhosamente apresentada àqueles que prestigiam o evento. $\mathrm{O}$ processo de preparação da roupa nova, entretanto, não fala apenas de uma noite especial, mas remete à agência de pessoas e de encantados - as entidades recebidas nas tendas - e também qualifica um tempo, o momento atual da religião na cidade.

Codó é conhecida na literatura das Ciências Sociais como cidade berço de uma religião afro-brasileira chamada terecô ou tambor da Mata, Encantaria de Barba Soeira, Brinquedo de Santa Bárbara e ainda Verequete. No terecô são "recebidos” encantados, entidades que tiveram uma vida terrena enquanto pessoas e que desapareceram, passando a viver na Encantaria. Nas noites de dança, embaladas pelo ritmo intenso das batidas dos tambores nas tendas, eles vêm para dançar, aconselhar e trabalhar "em cima" dos seus "cavalos". A cidade de Codó possui encantados específicos, os encantados da mata, que são comandados por Légua Boji Buá da Trindade - chefe de uma numerosa família de entidades, em sua maioria afeita à dança, à confusão e ao consumo de bebida alcoólica, conhecedora das matas e da lida com os animais do campo, especialmente com os bois.

Além dos encantados tradicionais do terecô, nas tendas da cidade é possível conviver com entidades de diferentes linhas do tambor de Mina maranhense, da umbanda - que teria sua primeira tenda construída em Codó ainda na década de 1930 e do candomblé - que chegou posteriormente, nos anos oitenta. A diversidade das entidades presentes em cada ritual tem relação direta com os diferentes ritmos de tambor tocados em cada uma das casas, visto cada ponto (ou cantiga) invocar determinado grupo de seres.

\footnotetext{
${ }^{1}$ Universidade Federal do Maranhão, Brasil.
} 
Uma tenda, barracão ou salão, como são chamados os espaços de realização dos rituais, possui seu pai ou mãe de santo, que chefia os filhos de santo que "brincam" sob seus cuidados. Como cada "brincante" do tambor recebe mais de um encantado, durante um mesmo ritual é possível conhecer diferentes entidades, que se comportam de formas variadas. Alguns destes encantados são considerados de origem remota, sendo lembrados como protagonistas das primeiras histórias contadas pelos terecozeiros (onde são chamados de "vodunsi antigos"), enquanto outros são reconhecidos como novos, pois seu aparecimento é tido como recente.

As roupas novas, como procurarei demonstrar na sequência do texto, durante o período da pesquisa de campo que fiz na cidade (pouco mais de um ano, entre 2010 e 2011) faziam parte de um grande investimento realizado nas tendas por ocasião dos festejos - ou seja, dos momentos de festa onde se homenageava uma entidade ou um santo. A costura destas peças - normalmente saia e bata para as mulheres, calça e camisa ou bata para os homens - era acompanhada pela reforma e pintura dos salões, pela troca das pequenas bandeiras de papel que decoravam o teto e pelas novas toalhas dos altares. Como as tendas eram, na maioria das vezes, construídas no fundo dos terrenos das casas de pais e mães de santo, também elas eram pintadas e decoradas por ocasião dos festejos. A beleza se tornava completa pela presença dos visitantes e pela abundância dos comes e bebes. Esse investimento em fazer uma "festa bonita” era entendido como uma preocupação recente na história do terecô, em contraposição ao tempo dos "vodunsi antigos". Ao falar sobre a passagem do tempo, as roupas novas também falam das transformações no âmbito da religião e desafiam algumas leituras realizadas sobre o tema nas Ciências Sociais, como procurarei demonstrar na continuidade do texto.

\section{Os "vodunsi antigos" e o tempo do terecô "forte"}

Em 1940, Octavio da Costa Eduardo esteve no Maranhão para estudar a presença negra no estado. Devido à sua formação e ao ambiente de produção acadêmica na época - marcado pela influência de Franz Boas e Melville Herskovitz (Silva, 2008) - Costa Eduardo (1948) pesquisou as relações raciais no Brasil, pensando-as a partir do conceito de aculturação. O autor analisou, de forma comparativa, os casamentos, a organização do trabalho e a religião dos negros em Codó e em São Luís - capital do estado. Nestas três esferas localizou sua preocupação sobre a aculturação das práticas africanas, 
reconhecendo que o terecô dos negros de Codó tinha sofrido grande impacto do cerceamento da liberdade no regime escravocrata, sincretizando-se com o catolicismo popular e mantendo fracamente as características que o autor reconhecia como provenientes da África. Como sinais deste enfraquecimento, a pesquisa aponta a presença dos santos no barracão onde se dançava tambor, o uso de pontos cantados e de nomes em português e o costume de batizar os encantados ao modo católico.

Na descrição destas características do terecô no povoado de Santo Antônio dos Pretos - lócus de sua pesquisa de campo no interior do município de Codó - Costa Eduardo (1948) também nos apresenta uma descrição das vestimentas dos "brincantes", dizendo que as mulheres usavam saias e blusas brancas, com panos em torno da cabeça e toalhas presas à cintura. Os homens, por sua vez, dançavam de calça, eventualmente com toalhas na cintura e, normalmente, com o torso nu. A simplicidade das roupas com as quais os encantados eram vestidos era acompanhada pelos poucos requisitos para a admissão de um participante no ritual e pela inexistência de uma cerimônia de iniciação para os neófitos. No tambor de Mina de São Luís, contrária e comparativamente, a herança africana estaria mais bem conservada.

Na mesma época, Nunes Pereira publica “A Casa das Minas” (1947), um estudo sobre a tenda de mesmo nome, a mais conhecida de São Luís. Nele, o autor afirma as características africanas do tambor de Mina da capital. Em seu livro, publicado um ano antes da obra de Costa Eduardo (1948), Nunes Pereira caracteriza a "pureza" na Casa das Minas, a distinguindo de outras religiões e práticas encontradas no Maranhão. Neste esforço, mostra como a religião e a feitiçaria eram distantes, de forma que, " $\mathrm{Na}$ "Casa das Minas" não se cuida de feitiçaria, isto é, da prática de malefícios ou do preparo de filtros, amuletos etc." (Pereira, 1947: 49). Indicando ainda a 'sobrevivência' dos traços africanos, o autor não vê semelhança entre os voduns e os santos católicos ou outras entidades caboclas e espíritas ${ }^{2}$.

A distinção tão aparente nas duas obras demonstra o que Barros (2007) pontua como uma valorização hierarquicamente diferenciada entre os tambores maranhenses, que reflete no âmbito religiões negras o que aconteceu com algumas manifestações culturais no estado: a valorização das características da vida na capital em oposição à

\footnotetext{
${ }^{2}$ Nas palavras do autor "Para a gente da Casa das Minas as suas divindades pertencem exclusivamente e essencialmente à teogonia africana, podendo vir da concepção religiosa deste ou daquele povo do Continente, mas nunca do seio da religião católica, do mundo dos pagés amazônicos ou dos "círculos" e "tendas" dos médiuns espíritas" (Pereira, 1947: 47).
} 
vida no campo. Segundo o autor, no início do século XX, com o declínio da elite rural, o Maranhão foi visto como ingressando em um momento de decadência econômica e 'cultural'. Neste cenário, um grupo de intelectuais e políticos colocou em primeiro plano as discussões sobre o progresso e sobre o renascimento do estado. Duas imagens passaram a ser associadas a São Luís: a de "Atenas Brasileira" - em uma referência à geração de Gonçalves Dias no século XIX; e a de "capital francesa" - remetendo à fundação da cidade a Daniel de La Touche (Barros, 2007).

No processo de 'renascimento' do Maranhão, São Luís passou a ter símbolos relacionados a uma intelectualidade branca e erudita, e a valores europeus. Como resposta a este movimento da intelectualidade local, vozes dissidentes buscaram retomar elementos da cultura negra e popular, vistos como fundamentais à identidade maranhense. Desta forma, algumas manifestações populares e negras se tornaram valorizadas como parte positiva da imagem do estado. Essa valorização, entretanto, foi seletiva, já que outras manifestações negras continuaram sendo desqualificadas, esquecidas e perseguidas pela polícia - criando uma distinção entre as manifestações negras (religiosas, populares) do centro da capital e aquelas do interior, que continuaram sem valor ${ }^{3}$.

Em “As religiões africanas no Brasil” (1971), Roger Bastide escreveu sobre as religiões afro-brasileiras do Maranhão a partir das obras anteriormente elaboradas sobre a presença negra no estado. Na parte do livro a qual me refiro neste texto, o autor discorreu sobre o contraste entre as religiões afro-brasileiras do interior e o tambor de Mina de São Luís. Para o autor, em torno de uma "ilha de resistência africana" - que seria a capital - existe uma "zona de transição onde o catimbó e o tambor de Mina abandonam-se às mais estranhas uniões" (Ibid.: 256) e onde a religião africana havia se misturado com outras práticas, encontrando diálogo com a pajelança indígena. Nestes locais, a tradição africana teria se conservado vagamente, existindo apenas uma "lembrança confusa da existência de alguns voduns daomeanos"4 (Ibid.: 258-259).

\footnotetext{
${ }^{3}$ Barros afirma que "Auto-identificando-se e demarcando a identidade da região, particularmente as elites e os letrados maranhenses, escolheram o que, em sua opinião, haveria de mais significativo no mundo europeu, os franceses oitocentistas e a Atenas do tempo de Péricles. Essa operação se repete no processo de definição da Casa das Minas como a mais pura e legítima tradição africana do Maranhão. Se há uma preocupação em destacar certos terreiros como os mais puramente africanos, as escolhas dos intelectuais revelam também uma preocupação em distinguir o afro-maranhense de outros afro-brasileiros" (Barros, 2007: 262).

${ }^{4}$ Voduns é a forma de denominar as entidades recebidas no tambor de Mina. Voduns daomeanos remete às entidades da Casa das Minas, que se acreditar ser fundada por mulheres negras que tinham como procedência o reino de Daomé, na África.
} 
Em sua análise, Bastide destaca a pobreza dos grupos negros rurais e o que considera a perda da exuberância dos trajes rituais e da complexidade dos processos de iniciação nestas religiões. A concepção da extrema simplicidade dessas práticas religiosas o permitiu concluir que, no interior, "Tem-se a impressão de se estar numa encruzilhada de religiões, ou antes, num beco sem saída em que se encontram as mais diversas místicas. Essas seitas em sua origem formaram-se provavelmente não sob o signo da fé, mas sob o manto da fraternidade na miséria" (Ibid.:261).

É provável que esta interpretação de Bastide participe de uma divisão marcante na produção sobre a presença negra no Brasil, que remete à distinção hierárquica entre as manifestações dos negros sudaneses e dos negros de origem banto. Em determinada literatura, como por exemplo, em Nina Rodrigues (1988; 2006), Arthur Ramos (1979) e Gilberto Freyre (2002) entre outros autores - e a despeito das diferenças entre seus trabalhos -, as religiões de origem sudanesa (como o tambor de Mina da capital) são vistas como mais puras, sofisticadas e importantes do que as de origem banto (provável origem do terecô). Neste sentido, para Bastide, a pobreza das pessoas do interior - e das suas religiões misturadas - reforçava a tendência à valorização das expressões jejedaomeanas do tambor de Mina da capital, que mantinham melhor conservadas as sobrevivências africanas.

Apresentando este breve quadro sobre a literatura que menciona o terecô - ou sua região de procedência, não procuro realizar uma crítica a estes autores - visto que para tal feito seria necessária uma maior contextualização das suas obras. Destaco apenas que se constituiu nesta literatura, uma narrativa que associava as religiões do interior do Maranhão com uma pretensa mistura de práticas (de cura, feitiço), vista como negativa, e que ressaltava uma simplicidade ou ausência de complexidade nas mesmas ${ }^{5}$. Minha intenção, neste texto, é mostrar que a simplicidade encontrada nos trajes, nos espaços rituais, nos ritos de iniciação e nos encantados, vista então como marca de uma religião menos africana e pobre, é compreendida de forma diferenciada pelos "brincantes" de Codó com os quais convivi durante o campo. Além disso, busco indicar como, a partir das roupas novas e dos adereços que as acompanham, temos uma teorização dos sujeitos sobre a religião e suas transformações.

\footnotetext{
${ }^{5} \mathrm{O}$ casal Sérgio e Mundicarmo Ferretti realizam diversas pesquisas sobre as religiões afro-brasileiras no Maranhão que problematizam e complexificam estas considerações (ver, por exemplo, S. Ferretti, 1996; M. Ferretti, 1998; 2000; 2001; 2003).
} 
Nas experiências da pesquisa na cidade de Codó, ouvi algumas narrativas sobre o passado do terecô. Tal como os autores comentados acima, também as pessoas que comigo conversavam falavam das décadas anteriores como um período de simplicidade no âmbito da religião - onde as roupas eram sem enfeites, assim como as festas. Naquele tempo, não havia salões e as celebrações eram realizadas dentro das matas e nas roças - longe dos olhos dos senhores donos das terras e da polícia que as perseguia. Os "brincantes" se deslocavam de forma discreta até estes lugares - à noite, em silêncio, em pequenos grupos e em filas - para não chamar atenção. Em um momento posterior, o terecô passou a ser feito em barracões construídos para este fim ou mesmo na casa de pais e mães de santo, onde era comum haver espaço para um altar com os santos (católicos). Não eram importantes, neste contexto, os elementos decorativos ou o luxo, era um tempo de "vodunsi antigo" e de religião forte.

Os "vodunsi antigos" eram os encantados conhecidos há muito tempo pelas pessoas. Normalmente eram aqueles relacionados à família de Légua Boji Buá e a alguns voduns do tambor de Mina - entidades já recebidas quando a umbanda e o candomblé eram menos populares ou inexistentes na cidade. Estes encantados eram diferentes dos mais 'novos' (aqueles conhecidos mais recentemente), por serem considerados bravos e duros, sendo afamados por punir os "brincantes" que não cumpriam com os seus pedidos - os fazendo bater as mãos intensamente contra pedras, correr durante horas, subir em árvores e mesmo causar sua morte.

Os "vodunsi antigos" não consideravam importante o uso de enfeites e de roupas bonitas ou a exuberância das festas e tendas. Eles não apenas não se importavam como puniam os "cavalos" que valorizavam esses aspectos. Era um tempo em que os encantados "não podiam ver um brinco, ver um enfeite na cabeça, que eles arrancavam" - me contaram duas "brincantes" durante um festejo. Querendo enfatizar a austeridade dos encantados antigos, elas disseram que, certa vez, quando uma terecozeira pintou as unhas para uma festa de tambor, o encantado que foi por ela recebido furiosamente tirou todo o esmalte e "Não foi nem com bucha de aço não, foi com ponta de faca”. Em uma entrevista ${ }^{6}$, o pai de santo Bita do Barão lembra que quando iniciaram as festas na sua tenda (fundada em 1954) os panos utilizados na

\footnotetext{
${ }^{6}$ Como afirmou o pai de santo, em entrevista cedida em 2004, para Ananias de Caldas, Pedro Sotero, Bacco Andrade e Marcelo Pedroso: "Assim que eu processava nossos trabalhos, com muita pobreza, as roupinhas com algodãozinho mesmo riscado. Eu me lembro dos tecidos todos, era riscado, algodãozinho, lonita, tricutô, rex, tupã, o nome dos tecidos, ai da Fábrica do Sebastião Archer" (em uma referência a um dos coronéis da cidade, diretor da Fábrica de Tecidos).
} 
confecção das roupas dos filhos de santo eram simples, de algodão, comprados na Fábrica de Tecido da própria cidade - cenário bastante diferente dos dias atuais, quando, por exemplo, as batas das filhas de santo podem ser bordadas em outros estados, como o Ceará.

No tempo da austeridade dos "vodunsi antigos" não havia noites de roupa nova, nem acessórios como brincos ou decoração de tendas. Estes aspectos não eram necessários porque as entidades não se importavam com eles. Aquele era um tempo de religião mais forte, ainda que as festas não fossem tão bonitas. Embora os encantados continuem não se importando com os enfeites, qualquer pessoa que frequente uma noite de tambor da cidade atualmente vai perceber a diferença em relação a este aspecto. Durante a minha pesquisa de campo, as/os "brincantes", especialmente nas festas, usavam brincos, maquiagem, esmalte e roupa nova. A percepção da alteração das roupas dos festejos era compartilhada pelos terecozeiros, que costumavam dedicar muito tempo à discussão sobre o modelo e as cores, as rendas e fitas, as costuras e bordados da indumentária de uma festa de tambor. Dentro da programação dos festejos, a roupa nova era usada na noite mais importante, quando se comemorava o aniversário de encantados ou o dia do santo homenageado.

Outro exemplo de mudança no âmbito das religiões afro-brasileiras da cidade se expressava na transformação do espaço físico das tendas. Segundo contavam pais e filhos de santo, os barracões, antigamente, não eram revestidos de lajotas, tinham chão "de terra". O contato com a terra era considerado importante para os terecozeiros, pois ela era vista como fonte de "força" dos encantados. Contudo, a grande maioria das tendas que conheci tinha o chão e, por vezes, as paredes, cobertos de lajotas e azulejos detalhes desejados pelos seus chefes e realizados assim que as condições financeiras permitissem.

As mudanças - das roupas, dos enfeites e da arquitetura das tendas - eram vistas pelos "brincantes" como alterações no terecô. Contudo, apesar delas, continuavam dizendo que os encantados não precisavam destes enfeites - tanto que a religião, antigamente, era mais forte. Sugiro aqui, entretanto, que esta percepção não deve ser lida como uma questão de profundidade/superficialidade (Miller, 2013), que nos faria ver que a atenção às 'aparências' modificaria uma espécie de 'essência' da religião. Ou seja, não gostaria de pensar nestas transformações como algo que faz perder um original ou algo mais verdadeiro. Essa compreensão, além de conter elementos bastante 
questionados pela antropologia (aos quais me refiro na sequência do texto), não explicaria a centralidade das falas sobre a beleza das tendas e das roupas como uma forma de homenagear os encantados e bem receber os visitantes.

\section{Um tempo de "roupa nova" e de "enfeites"}

Algumas noções são compartilhadas, no senso comum e nas ciências sociais, no que concerne às religiões afro-brasileiras, sobre a importância das roupas utilizadas nos rituais em homenagem às entidades. É sabido que, no âmbito das relações com os orixás, por exemplo, cada um deles é referenciado por cores específicas ligadas a sua mitologia, que marcam os trajes e os colares de conta (chamados também de guias ou rosários) utilizados por seus filhos de santo (Elbein dos Santos, 1977; Prandi, 2001). Igualmente, se sabe sobre a relação da história de cada orixá com determinados materiais que compõe seus objetos rituais. Além disso, em outros contextos, a escolha dos tecidos e das rendas indica para aspectos da vida das entidades e também para graus de diferenciação entre filhos de santo de uma casa (Baptista, 2007). Neste sentido, cores, materiais e tipos de tecidos e bordados indicam para um significado vinculado à mitologia das entidades e à hierarquia nas casas.

A feitura das roupas e dos colares no tambor da Mata de Codó era também uma preocupação frequente, sendo assunto recorrente nas conversas cotidianas entre pessoas que frequentam tendas de religião afro-brasileira. $\mathrm{Na}$ tenda de Dona Luizinha - um espaço pequeno de culto, localizado no fundo do terreno de sua casa -, todos os anos, no festejo realizado em homenagem a São Francisco de Assis, era costurada uma roupa nova, tanto para a mãe e as filhas de santo, como para o padrinho e os tamborzeiros do local. Meses antes do festejo, Dona Luizinha costurava uma miniatura da saia e da blusa das "brincantes", com as quais vestia uma boneca que servia como protótipo para a visualização do modelo. Depois disso, comprava o tecido em uma conhecida loja do centro da cidade e, de forma parcelada, o revendia às filhas de santo e aos outros participantes do ritual. Na casa de Dona Luizinha, os preparativos que envolviam o coser de uma roupa nova tinham início muitos meses antes do festejo. Encontrar tecido suficiente para as roupas na cidade era uma das preocupações, assim como encontrar as rendas e fitas coloridas para os detalhes.

Tudo começava na sequência do festejo anterior, quando algum dos encantados “carregados" por um pai ou mãe de santo, em uma das suas aparições, narrava aos 
filhos de santo qual a cor e a forma da roupa do ano seguinte. As formas normalmente eram semelhantes: as mulheres usavam uma bata e uma saia (que levava, costumeiramente, cerca de oito metros de pano), os homens usavam camisa ou bata, e calça. O que podia mudar era a forma da bata e a existência ou não de camadas em uma saia. Outros elementos, como as rendas, bordados e fitas, contudo, apresentavam variação de um ano para outro. Comentava-se que as rendas e as fitas saíam mais caras do que os tecidos. Já os bordados eram considerados muito caros e dançar com uma bata ou uma toalha bordada presa à cintura era sinal de grande investimento do "brincante".

Depois da definição das roupas, dada pelos encantados, seu pedido passava pelo crivo da disponibilidade do material na cidade. Alterações na escolha original poderiam ser feitas de acordo com aquilo que se encontrava, ou não, nas lojas codoenses. Se uma renda não era encontrada, por exemplo, ela poderia ser substituída por outra considerada semelhante (por possuir as mesmas cores). A etapa seguinte era a costura de uma primeira roupa que serviria como modelo para as indumentárias. O conhecimento do ato de coser era compartilhado por muitas mulheres da cidade, de forma que, em casas como a de Luiza, com oito filhas de santo, houvesse duas 'costureiras de santo'.

A feitura da roupa, portanto, congregava a contribuição de diferentes agências. Por um lado, como comentei no parágrafo anterior, dela participavam os encantados. Por outro lado, existia a ação dos sujeitos diante das condições do mercado de tecidos e enfeites da cidade, que os conduzia a fazer escolhas nem sempre coincidentes com as determinações das entidades. Em uma terceira menção, cabe destacar o papel das diversas mulheres - "brincantes" ou não (ou seja, parentes, vizinhas etc.) - que costuravam as grandes saias rodadas, batas, camisas e calças - e que, neste processo, poderiam fazer alterações na indumentária durante a feitura.

O movimento em torno das roupas novas fazia parte da organização do festejo de uma tenda. Nestes momentos, também o espaço físico do barracão e da casa do pai ou mãe de santo era embelezado. Cada ano, os investimentos diferiam, pois estavam condicionados a diversos fatores, entre os quais a condição financeira da família do pai ou mãe de santo, a lavoura, o investimento do ano anterior etc. Para as festas, os salões poderiam receber uma nova pintura, a troca das toalhas, a inclusão de um santo no altar, novas bandeiras coloridas no teto, flores de plástico, desenhos de anjos, santos ou pontos de alguma entidade desenhados nas paredes laterais. Em alguns momentos era 
possível pintar ou mesmo trocar os tambores da casa, estender bandeiras até a rua, construir um novo cruzeiro, dar novas cores também à casa do pai ou mãe de santo, fazer pequenas obras para o conforto dos visitantes.

Além destes diferentes atos de embelezamento do espaço físico das tendas, fazer uma "festa bonita" implicava em bem receber os visitantes - familiares, vizinhos, clientes e "brincantes" de outras tendas da cidade - com abundância de comida e de bebida. Os visitantes ainda eram recebidos com homenagens durante a dança do tambor - ou seja, eram anunciados quando entravam na tenda, com a menção do nome de seu pai ou mãe de santo e com a disponibilização do microfone para que pudessem cantar o ponto de seu desejo (quando retribuíam os agradecimentos com a mesma generosidade e o uso de superlativos).

Independente da quantidade de noites de duração de uma festa, a noite mais importante era a da roupa nova. Nela eram recebidos os fotógrafos contratados para fazer os registros e o maior número de visitantes - que poderiam simplesmente assistir ou também dançar. As roupas, padronizadas nas cores escolhidas para o ano, eram idênticas, assim como normalmente eram os colares de conta. Apesar disso, cada filho ou filha de santo usava outros colares, pulseiras, anéis e relógios. A preparação para a entrada no salão era feita nas dependências da casa do próprio pai de santo ou em algum vizinho que ajudava no festejo. Era onde as filhas e filhos de santo da casa tomavam banho, preparavam cabelo e maquiagem para o esperado momento do ingresso no salão. Em síntese, a roupa nova era parte fundamental de uma "festa bonita", que incluía a decoração das tendas, a oferta de comes e bebes, as palavras de generosidade e grandeza dedicadas aos da casa, aos encantados e aos visitantes.

\section{Pensando a partir dos enfeites e das roupas}

Embora fosse fundamental fazer uma "festa bonita", para demonstrar grandiosidade e homenagear os encantados - entre possíveis outras razões - pais e filhos de santo, quando falavam sobre estes temas, continuavam concordando que a beleza era uma marca contemporânea da religião. No passado, como mencionei em trecho anterior do texto, o investimento nas roupas novas, e mesmo na decoração das tendas, não existia. Nesta perspectiva, em alguma medida os sujeitos invertiam parte da prerrogativa de Bastide: hoje a festa é mais bonita - e mais rica - porém a religião, antigamente, era mais forte. Entre convites para festejos, opiniões sobre roupas novas e escolha de 
tecidos, como pensar estes investimentos (importantes e dispendiosos) na beleza, se a reza e a festa aconteciam sem eles?

Parece-me evidente que existem diversas respostas para esta pergunta. Algumas delas poderiam associar o aumento da atenção com as roupas e com os enfeites a uma possível melhoria da condição financeira dos terecozeiros; igualmente, se poderia sugerir que a chegada de outras religiões afro-brasileiras, conhecidas pela valorização do vestuário, como o candomblé, levou a uma maior apreciação das roupas no âmbito das "brincadeiras". Estas explicações, entretanto, tendem a reduzir as mudanças e transformações a determinado elemento - como a economia ou a imitação das outras casas - tomando de forma unidimensional o que acontece ou mesmo sugerindo alternativas do tipo 'causa e efeito', incapazes de dar conta daquilo que vivem e fazem os sujeitos. Pretendo colocar estas respostas em suspenso por enquanto, na medida em que acredito que elas pouco ou nada nos ajudam a entender a beleza e os investimentos atuais nas roupas novas nas tendas codoenses (e, de certa forma, como vou sugerir no final do texto, a própria experiência religiosa dos "brincantes”).

Evidentemente, essas colocações nos remetem a questões teórico-metodológicas da antropologia. Já nos trabalhos clássicos e inaugurais da antropologia cultural/social a partir da segunda metade do século XIX - existe um interesse em objetos, vestimentas, acessórios, artefatos - do âmbito cotidiano e ritual de grupos considerados não ocidentais (e que figuram nesta literatura sob o termo "primitivos"). Por um lado, fica evidente o afã colecionador que constitui, na época, diversos museus ou seções de arte primitiva em diferentes contextos ${ }^{7}$; por outro, para além da possibilidade de acessar o exótico ou a diversidade por intermédio destas coleções, este conjunto de elementos permitiu ainda uma discussão sobre o que é antropologia, quais seus recortes de estudo e sua abordagem metodológica.

Franz Boas (1996), no livro "Arte Primitiva”, de 1927, sugere pressupostos teórico-metodológicos para o estudo da arte que não divergiam das prerrogativas que instituíra para o estudo dos diferentes grupos culturais - a saber, o respeito ao pressuposto da unidade psíquica da humanidade e o reconhecimento do particularismo histórico (e desta forma, do caráter dinâmico da cultura). Sua análise dos objetos de arte primitiva os classifica em dois grandes grupos - aqueles onde a preocupação com a

\footnotetext{
${ }^{7}$ Sobre a importância das coleções para a antropologia, assim como uma crítica a esta perspectiva, ver Clifford (1994) e Price (2000).
} 
forma é fundamental (onde se percebe a simetria, a uniformidade e a repetição rítmica dos elementos), onde "O interesse formal deve-se, diretamente, à impressão que deriva da forma" (ibid.: 54); e a arte representativa, onde "o próprio termo implica que o produto artístico represente um pensamento ou uma ideia" (Ibid.: 55).

As sugestões de Boas, bem sabemos, nascem da tentativa de dar conta de elementos não suficientemente explicados, para o autor, na perspectiva do evolucionismo social e no difusionismo. A possibilidade de similaridade entre formas artísticas não deveria, portanto, ser explicada por estágios ascendentes de desenvolvimento de uma história única da humanidade, ou por um contato original com uma posterior dispersão, mas pelas particularidades históricas e culturais que se envolvem em processos de aculturação (dada à importância da tradição), já que "a originalidade da produção artística está condicionada à manipulação criativa, e não à invenção absoluta" (Almeida, 1998: 21).

Suas respostas em relação à arte, contudo, para Lévi-Strauss (1970), não cumprem a tarefa de explicar as recorrências entre estilos e formas de representar presentes em objetos de arte em diferentes partes do mundo. A possibilidade de uma resposta condizente seria possível, para o autor, a partir de uma abordagem estruturalista $^{8}$, capaz de explicar analogias e semelhanças na arte. Lévi-Strauss se dedica a tal proposta ao comparar o desdobramento na arte produzida em diferentes partes do mundo - como nos indígenas Cadiuéu no Brasil, os Maori da Nova Zelândia, os habitantes da costa noroeste dos Estados Unidos, da Sibéria e a China Arcaica. Como mostra o autor, nestes grupos, também podemos falar em dualismo entre dois elementos decorativos - um formal e outro representativo, que "se transforma em outros dualismos: escultura e desenho, rosto e decoração, pessoa e personagem, existência individual e função social, comunidade e hierarquia" (ibid.: 298). A dualidade seria evidente na independência recíproca do elemento plástico e do elemento gráfico da arte, que por sua vez, remeteriam "ao jogo mais flexível entre a ordem social e a ordem sobrenatural, como o desdobramento da representação exprime a aderência estrita do ator a seu papel, e da posição social aos mitos, ao culto e aos pedigrees" (ibid.: 302).

\footnotetext{
${ }^{8}$ Nas palavras do autor: "Se a história, solicitada sem trégua (que é preciso solicitar em primeiro lugar), responde não, então voltemo-nos para a psicologia ou para a análise estrutural das formas, e perguntemonos se conexões internas, de natureza psicológica ou lógica, não permitem compreender recorrências simultâneas, com uma frequência e uma coesão que não podem resultar do simples jogo das probabilidades. É neste espírito que trarei agora a minha contribuição ao debate" (Lévi-Strauss, 1970: 283).
} 
A análise estruturalista da arte, portanto, demonstraria seu caráter representativo, ao perceber, nas similaridades dos objetos e pinturas, semelhanças ou princípios encontrados também em outros espaços, como a organização social dos grupos, seus sistemas de prestígio e nobreza, sua concepção de sujeito. É sobre este aspecto - que seja, a necessidade de uma explicação para arte que recorra a elementos exteriores ao próprio contexto do grupo, que repousa a crítica de Clifford Geertz (1997) ao trabalho de Lévi-Strauss. Para este autor, a antropologia (de uma maneira geral e não apenas no estudo da arte), deve se interessar pelos sentidos e significados fornecidos pelos sujeitos àquilo que fazem ${ }^{9}$. Neste sentido, sua proposta de um conceito semiótico de cultura se baseia na observação (e na descrição densa) do comportamento dos sujeitos. Por um lado isso indica que o estudo da arte e da estética não "pode se dar fora do curso normal da vida social" (ibid.: 146) e que é neste âmbito que se compartilham os significados também presentes na arte; por outro lado, a observação do comportamento não se prende ao comportamento em si, mas ao fato de que nele se evidencia o significado das ações dos indivíduos. Neste sentido, não é a forma, a cor ou o traço que importariam, mas ligações e conteúdos (para o autor, mais profundos) que tornariam objetos, gravuras e poesias, por exemplo, importantes.

\begin{abstract}
é essa conexão com o que é a realidade social que revela seu poder construtivo. A unidade da forma e do conteúdo é, onde quer que ocorra, e seja em que grau ocorra, um feito cultural e não uma tautologia filosófica. Para que possa existir uma ciência semiótica da arte, é preciso que esta explique esse feito. E, para explicá-lo, terá que dar mais atenção - do que normalmente se predispõe a dar - ao que se fala e ao que se fala além do discurso reconhecidamente estético (ibid.: 154).
\end{abstract}

Daniel Miller (2013) demonstra os limites da apreensão semiótica para o estudo das indumentárias e das roupas. Para o autor, esta abordagem privilegia uma ontologia ocidental do sujeito, na medida em que reforça a distinção entre aparência (exterioridade) e espírito (interioridade), dando valor de superioridade e profundidade ao segundo destes elementos.

\footnotetext{
9 "É claro que qualquer coisa pode ajudar uma sociedade a funcionar, inclusive a pintura e a escultura; como também qualquer coisa pode ajudá-la a se destruir totalmente. A conexão central entre a arte e a vida coletiva, no entanto, não se encontra neste tipo de plano instrumental e sim em um plano semiótico. A não muito indiretamente, os rabiscos coloridos de Matisse (em suas próprias palavras) e as composições de linhas dos iorubá não celebram uma estrutura social nem pregam doutrinas úteis. Apenas materializam uma forma de viver, e trazem um modelo específico de pensar para o mundo dos objetos, tornando-o visível" (Geertz, 1997: 150).
} 
O problema da semiótica é que ela faz das roupas meros servos, cuja tarefa é representar o imperador - o espírito humano. As roupas obedecem as nossas ordens e nos representam no mundo exterior. Em si mesmas, são criaturas sem valor, superficiais, de poucas consequências, simples trecos inanimados (Miller, 2013: 22).

A partir de dois casos etnográficos - as roupas em Trinidad e o sári na Índia -, o autor sugere que a indumentária pode ser considerada algo fundamental na constituição de uma noção de sujeito diverso daquele da premissa ocidental, na medida em que é ele é entendido exatamente por aquilo que aparenta ser e não como portando um eu verdadeiro e profundo. A perspectiva do autor pode ser associada com outras ênfases (antropológicas ou não) que têm chamado atenção para o limites de análises centradas na representação, que colocam em segundo plano aquilo que os sujeitos fazem (pensando na ação, na prática, no acontecimento) e, ao mesmo tempo, aquilo que é feito com eles (pensando em como as coisas fazem as pessoas ou se impõe sobre o mundo social $)^{10}$.

Os estudos de ritual e performance, por exemplo, especialmente aqueles realizados nas últimas décadas do século passado, enfatizam a importância da ação não apenas como momento de reprodução da vida social - e, portanto, de continuidade dos sentidos já instituídos culturalmente, mas como espaço de transformação e abertura de significados (Bauman e Briggs, 2008; Schechner, 2012; Cardoso, 2007). Existe uma influência da linguística nesta abordagem, que permite perceber a importância das coisas ditas pelos sujeitos como constitutivas da realidade que compartilham - Austin (1975), por exemplo, indica a capacidade das locuções produzirem aquilo que enunciam - ou a capacidade de, parafraseando o título de sua obra, fazer coisas com palavras (Austin, 1975; Peirano, 2001). Esta perspectiva não nega a existência dos sentidos compartilhados pelos sujeitos, mas destaca a importância do ato como momento fundamental da vida social, pois, é no fazer (ou no falar) que os significados podem ser expandidos e mesmo transformados.

Além da ênfase dos estudos de performance, também determinada abordagem no estudos dos objetos tem chamado atenção para a importância da ação. A partir do questionamento da distinção entre sujeito e objeto, se enfatiza como este último não é inanimado, mas causa impactos, efeitos ou consequências nas relações sociais. Pensando a arte como um sistema de ação e não de representação, Alfred Gell (1998,

${ }^{10}$ Como lembra Pereira (2013), ao comentar o destaque os 'rolezinhos' no segundo semestre de 2013: "Há uma nova tendência na discussão antropológica afirmando que não podemos entender as coisas apenas como representação ou resultado do social. Precisamos pensar também em como as coisas fazem as pessoas e mesmo o social" ( $\mathrm{s} / \mathrm{d})$. 
2005) enfatiza a mobilização dos princípios estéticos na interação social (ou papel dos objetos na vida social) - esfera onde, efetivamente, coisas e pessoas adquirem significado. A obra de arte, neste sentido, é inerentemente social porque se coloca entre dois sujeitos, circulando e criando uma relação entre os mesmos. Haveria, desta forma, uma participação dos objetos nas relações sociais e mesmo uma homologia entre a produção de um objeto de arte e a criação e manutenção destas relações.

A antropologia, portanto, tem nos objetos um campo importante de discussão (aqui apresentado de forma breve), não apenas sobre como compreender a arte e a produção da materialidade, mas também a interação e as relações sociais, colocando uma importante discussão teórico-metodológica sobre significado e ação. Na próxima seção do texto, procuro pensar a importância da noite da roupa nova - ou seja, das indumentárias e dos acessórios que as acompanham no corpo dos "brincantes" do terecô - a partir destas provocações e de situações vividas em campo. Busco, neste sentido, pensar como essa discussão nos ajuda a imaginar as formas com as quais os sujeitos se posicionam diante do mundo.

\section{Um colar para combinar com a roupa}

Em diversas experiências durante o campo sentimos que nossas perguntas apresentam limites ou mesmo são inadequadas diante daquilo que vivemos. Certa vez, compartilhei uma experiência com uma mãe de santo, que chamou minha atenção neste sentido. A situação aconteceu no tempo que antecedia a festa na tenda de Mestre Bita do Barão, o pai de santo mais conhecido da cidade. Eu estava na casa de Dona Luizinha, sentada em frente à sua residência, quando chegaram duas filhas de santo e uma de suas filhas consanguíneas. Dentro de uma das sacolas plásticas que traziam da caminhada no sol escaldante estava o modelo do colar de contas que usariam na noite da roupa nova, no festejo da casa do Mestre. Lá, Luiza e suas filhas de santo se vestiam como as pessoas da casa, porque "brincavam" também naquela tenda.

Embora já tivesse comprado suas miçangas, Dona Luizinha esperava pelo modelo do colar, pois era importante que ele ficasse idêntico ao dos outros filhos de santo - e ela estava em dúvida quanto à sequência das cores das pequenas pedras. Interessada na escolha das cores, eu perguntei por que naquele ano as miçangas eram vermelhas, brancas e verdes. Esperava, provavelmente, que me contassem sobre a relação com os 
encantados ou com alguma entidade homenageada, destrinchando significados e histórias de vida dos mesmos. Dona Luizinha, em sua grande paciência com as minhas intermináveis perguntas - para ela tantas sem sentido -, me respondeu que "é dessa cor para combinar com a roupa". Fiquei pensando na resposta - não apenas porque para mim o modelo tricolor não combinava com o branco e o amarelo das roupas novas mas porque Luizinha descortinou uma função digna de nota: a combinação, a beleza, o ficar bonito, era fundamental. Dizia ela que, na hora em que as filhas de santo entrassem no salão, deslumbrantes nas suas roupas novas para a festa das princesas, a combinação da roupa com o colar ficaria bonita.

Cabe considerar que existem sim objetos que remetem a determinados encantados e suas famílias (S. Ferretti, 1996). Entretanto, segundo Luiza, aquele não era o caso. De fato, as roupas novas e os colares de conta usados nestas noites especiais eram padronizados - independiam de quem os usasse. Particularizações aconteciam em alguns casos - como uma das filhas de santo que sempre variava o modelo da roupa de forma a homenagear uma entidade que recebia -, ou ainda de acordo com as possibilidades de pagar o bordado em uma bata ou toalha. Entretanto, o importante e o valorizado nas noites de roupa nova era que elas mantivessem uma uniformidade entre si. Em outros contextos, a uniformização das roupas foi identificado com a espetacularização de performances tradicionais (para o tambor de crioula, ver S. Ferretti, 2002), entretanto, em Codó, era considerada elemento embelezador dos festejos da cidade.

A resposta de Luiza, ao esboçar a combinação entre os acessórios e a roupa como razão suficiente para explicar a escolha das cores do colar de contas era uma precaução para duas explicações que já estavam delineadas no meu raciocínio - e que muito pouco explicariam as experiências que eu vivia em campo. Primeiro, ela destoava da perspectiva de haver um significado que sustentaria a escolha das cores e que estaria para além dessa própria escolha - como, por exemplo, nas características de alguma entidade ou encantado. Segundo, também não se utilizava de outra explicação comum no âmbito das argumentações sobre religião afro-brasileira - a questão da origem, ou seja, não explicava a eleição das cores como algo tradicional ou cultural (no sentido simplista dessas palavras) - o que remeteria a justificativa da escolha a outro tempo que não o presente. A resposta da origem, neste sentido, se aproxima da resposta sobre o significado, quando nossa atenção se desloca da própria prática e existência das coisas, em busca de algo que sustente seu aparecimento (quando a prática se torna secundária 
em relação ao sentido que a anima). Nesta situação, pensando naquilo dito por Luiza, não interessava uma representação transcendente ao próprio objeto - o que nos lembra as colocações de Miller (2013) em sua crítica à semiótica - e que poderiam aqui ser estendidas à perspectiva estruturalista (a despeito das divergências entre ambas).

Evidentemente, essa não foi, nem de longe, a única pergunta que fiz que se desdobrou de forma inesperada nas respostas dos meus interlocutores de pesquisa. Outras vezes, nas quais perguntava sobre o acender das velas ou a ordem das músicas cantadas em algum ritual, recebia respostas que poderiam ser resumidas na expressão (que também ouvi literalmente): "é assim porque é”. Uma das formas de olhar para este tipo de resposta seria dizer que existem coisas que são do âmbito do segredo e que não deveriam ser compartilhadas comigo (como um pretenso significado das cores). Todos sabemos que os conhecimentos do âmbito da liturgia ou da ritualística de determinadas religiões não podem e não são compartilhados com não iniciados (como era meu caso) e mesmo com iniciados depende do seu tempo no culto e seu desenvolvimento espiritual. Essa poderia ser minha aposta de interpretação destas respostas, ou seja, dizer que elas seriam apenas uma forma de afirmar que existem coisas sobre as quais eu não poderia saber. Neste sentido, tal configuração chamaria atenção para os limites e o conhecimento não totalizante que temos nas nossas pesquisas (sejam elas sobre religião, política, sexualidade etc.).

Mas, para além da afirmação de que nosso conhecimento é sempre parcial, existe, em minha opinião, outra possibilidade de pensar estas respostas que não nos remetem ao significado ou à origem. Isso implica a possibilidade de compreender frases como "é assim porque é" e "é assim porque significa tal coisa" como simetricamente importantes. Neste sentido, respostas como 'o colar é desta cor para combinar com a roupa' deveriam ser igualmente levadas a sério como centrais para falar sobre o modo como os sujeitos vivem e compreendem aquilo que fazem.

Para pensar a resposta de Luiza, entretanto, não estou sugerindo que precisamos criar uma teoria da relação entre as cores na visão dos pais e mães de santo de Codó. Acredito que, a combinação das cores, nessa narração - que torna significados, origem e mesmo a escolha dos encantados secundária - nos remete diretamente ao momento de entrada de pais e mães de santo nas tendas em festa (o que destacaria o papel dos objetos e do fazer no momento da ação - Bauman e Briggs (2008); Gell (1998, 2005). Sugiro aqui, que os objetos - as roupas, os colares - causam impacto naqueles que 
esperam a entrada majestosa de pais e filhos de santo na tenda e, desta forma, produzem a própria situação do festejo.

Este momento - em que a combinação entre roupas e acessórios aparece e toma forma - não nega, evidentemente, o processo anterior de preocupação e investimento nas roupas novas e na festa. Pelo contrário, é no fazer do festejo que as roupas novas e os colares mostram o encadeamento de relações sociais necessárias aos seus processos produtivos (Gordon, 2009). Neste sentido, uma festa bonita só é possível pela ação e engajamento daqueles que se vestem e vestem suas casas para a festa, do dinheiro coletivo empregado na produção da beleza, nas diversas mãos pelas quais passam o tecido, as rendas, o cozinhar dos bolos e dos comes. Além disso, é no festejo que se expressam as relações mantidas entre as tendas, por intermédio do "pagar noite" dos visitantes $^{11}$; assim como se expressam as relações entre entidades, santos e pessoas evidentes nas homenagens, salvas e vivas.

Roupas novas e acessórios são, portanto, produtores dos festejos e das relações sociais (das quais também são signos). Sugiro, inspirada em Gordon (2009), que há nestes processos também um valor da beleza, não apenas estético, mas ético e quiçá ontológico. Ao sinalizarem para as relações sociais que permitem sua própria existência, roupas novas e colares contribuem para a existência dessas relações, mas não qualquer existência - uma existência pautada pela beleza da combinação das cores.

\section{Considerações finais}

A guisa de conclusão deste texto, gostaria de recuperar alguns elementos mencionados nas páginas anteriores para dar um fechamento ao argumento aqui apresentado. Neste artigo procurei esboçar algumas considerações sobre as roupas novas - uma indumentária ritual costurada de forma anual, especialmente para o festejo mais importante de cada tenda de religião afro-brasileira de Codó. As roupas novas não tem um caráter de novidade apenas porque anualmente inéditas, mas também porque percebidas como uma das características recentes do terecô na cidade.

Elas são um dos elementos que fala da transformação da religião, das mudanças no âmbito dos seus rituais, dos espaços de culto e do comportamento dos encantados.

\footnotetext{
11 "Pagar noite" é a forma local de designar as visitas que são feitas entre as tendas no momento de seus festejos. Nesta perspectiva, uma tenda que recebe outro salão visitante, precisa devolver esta visita na sua festa (Ahlert, 2012).
} 
Em período anterior, os "vodunsi antigos" eram duros, costumeiramente aplicavam castigos aos seus "cavalos" e não gostavam de enfeites, acessórios e cuidados com a aparência. Naquele tempo, apesar da simplicidade das roupas, dos acessórios e dos rituais - e discordando da bibliografia que via nestes elementos uma representação de uma religião pobre e negativamente sincrética - o terecô era mais forte.

O tempo atual, das roupas exuberantes e dos festejos pomposos, se distancia da religião de anos atrás, onde tudo era humilde, onde os barracões eram de barro e palha, onde havia apenas café para servir aos visitantes. Sugeri que essa distinção entre um tempo de religião forte e o atual, não fosse percebida como uma oposição interioridade (força) versus cuidado com a aparência (enfraquecimento). Antes, este texto foi uma tentativa de falar sobre a importância dada à produção de uma festa bonita, marcada pelos enfeites, pela abundância e por uma decoração cuidadosa.

Os colares e as roupas, na medida em que eram temas centrais das conversas e das preocupações dos sujeitos, também ajudam a deslocar nosso olhar das respostas relativas ao significado e à origem das escolhas religiosas do grupo, e pensar na emergência dos sentidos na experiência. Desta forma, ao apresentar nova decoração e nova roupa nos festejos, é importante destacar o momento em que as expectativas tomam forma e causam sensações naqueles que participam dos rituais - "brincando" ou apenas assistindo. A combinação entre os elementos ou suas cores - enquanto razão mencionada em campo para a determinação da forma destes 'artefatos' mostram a importância da beleza na constituição dos festejos. Desta forma, ao nos permitir falar sobre a passagem no tempo nas histórias que contam os terecozeiros, as roupas novas chama atenção não apenas para as cronologias, mas para as agências, as participações e o engajamento dos sujeitos com a beleza que permeia as festas. Por fim, tendo este investimento na beleza como central, o colar para combinar com a roupa também pode ser pensado como um desejo, um ato de afirmação de como os sujeitos gostariam de ser percebidos ou como se postam diante do mundo.

\section{Referências}

AHLERT, Martina. 'Pagar noite' ou 'pagar tambor': a circulação de encantados, pais e filhos de santo em Codó (MA). Boletim da Comissão Maranhense de Folclore, v.53,2012: 11-13.

Cidade Relicário: uma etnografia sobre terecô, "precisão" e Encantaria em Codó (Maranhão). Tese (doutorado). Programa de Pós-Graduação em Antropologia Social. Universidade de Brasília, 2013. 
ALMEIDA, Kátia Maria Pereira de. Por uma semântica profunda: arte, cultura e história no pensamento de Franz Boas. Mana, 4 (2), 1998: 7-34.

AUSTIN, J.L. How to do things with words. Harvard Univ. Press, 1975.

BAPTISTA, José Renato de Carvalho. Os deuses vendem quando dão: os sentidos do dinheiro nas relações de troca no Candomblé. Mana, Rio de Janeiro, v.13, n.1, 2007: 07-40,

BARROS, Antonio Evaldo Almeida. O Pantheon Encantado: culturas e heranças étnicas na formação de identidade maranhense (1937-65). 2007. Dissertação (Mestrado em Estudos Étnicos e Africanos) - Programa Multidisciplinar de Pós-Graduação em Estudos Étnicos e Africanos, Universidade Federal da Bahia, Salvador. 2007.

BASTIDE, Roger. As religiões africanas no Brasil: contribuição a uma sociologia das interpretações de civilizações. São Paulo: Pioneira Editora, 1971: 243-266.

BAUMAN, R. BRIGGS, C. Poética e performance como perspectivas críticas sobre a linguagem e a vida social. Revista Ilha, vol. 8, n. 1 e 2, Florianópolis, 2008.

BOAS, Franz. Arte Primitiva. Lisboa: Fenda Edições, 1996.

CARDOSO, Vânia. Narrar o mundo: estórias do "povo da rua" e a narração do imprevisível. Mana, Rio de Janeiro, v.13, n. 2, 2007: 317-345

CLIFFORD, James. Colecionando arte e cultura. In: Revista do Patrimônio Histórico a Artístico Nacional, n. 23, 1994.

COSTA EDUARDO, Octávio. The negro in Northern Brazil: a study of acculturation. New York: J.J. Austin Publisher, 1948.

ELBEIN DOS SANTOS, Juana. Os Nagô e a Morte: Padè, Asèsè e o Culto Égun na Bahia. 2.ed. Petrópolis: Vozes, 1977.

FERRETTI, Mundicarmo Maria Rocha. Terecô: a linha de Codó. In: VIII Jornadas sobre Alternativas Religiosas na América Latina, São Paulo, 1998.

Desceu na guma: o caboclo do Tambor de Mina em um terreiro de São Luís - a Casa Fanti-Ashanti. 2.ed. São Luís: EDUFMA, 2000.

. Encantaria de Barba Soeira: Codó, capital da magia negra?. São Paulo: Siciliano, 2001.

Formas sincréticas de religiões afro-americanas: o Terecô de Codó - MA. Cadernos de Pesquisa, São Luís, v. 14, n. 2, jul./dez. 2003: 95-108

FERRETTI, Sérgio Figueiredo. Querebentã de Zomadonu: etnografia da Casa das Minas do Maranhão. 2.ed. São Luís: EDUFMA, 1996.

Folclore, 2002.

Tambor de Crioula: ritual e espetáculo. 3.ed. São Luís: Comissão Maranhense de

FREYRE, Gilberto. Casa Grande \& Senzala. Rio de Janeiro: Record, 2002.

GEERTZ, Clifford. Arte como um sistema cultural. In: O Saber Local. São Paulo: Vozes, 1997. 
GELL, Alfred. Art and agency. An anthropological Theory. Claredon Press Oxford, 1998. 2005: 41-63

A tecnologia do encanto e o encanto da tecnologia. Concinnitas, ano 6, v. 8 (1),

GORDON, César. $O$ valor da beleza: reflexões sobre uma economia estética dos objetos entre os Xikrin (Mebengokre-Kayapo). Série Antropologia, n. 424, Brasília, 2009.

LEVI-STRAUSS, Claude. O desdobramento da representação nas artes da Ásia e da América. In: Antropologia Estrutural I. Rio de Janeiro: Tempo Brasileiro, 1970.

MILLER, Daniel. Por que a indumentária não é algo superficial. In: Trecos, troços e coisas: estudos antropológicos sobre a cultura material. Rio de Janeiro: Zahar, 2013: 21-65.

NAKASHIMA, Edson. ALBUQUERQUE, Marcos Alexandre. A cultura política da visibilidade: os Pankararu na cidade de São Paulo. Est. Hist., Rio de Janeiro, vol.24, n. 47, 2011.

PEIRANO, Mariza (org.). O dito e o feito. Ensaios de antropologia dos rituais. Rio de Janeiro: Relume Dumará, 2001.

PEREIRA, Nunes. A Casa das Minas: contribuição ao estudo das sobrevivências daomeianas no Brasil. Publicações da Sociedade Brasileira de Antropologia e Etnologia, Rio de Janeiro, n. 1, mar. 1947.

PEREIRA, Alexandre Barbosa. Entrevista. In: BRUM, Eliane. Os novos vândalos do Brasil". 2013. Disponível em: http://www.geledes.org.br/em-debate/colunistas/22538-rolezinhos-o-queestes-jovens-estao-roubando-da-classe-media-brasileira-por-eliane-brum.

PRANDI, Reginaldo. Mitologia dos Orixás. São Paulo: Companhia das Letras, 2001.

PRICE, Sally. Arte primitiva em centros civilizados. Rio de Janeiro: Editora da UFRJ, 2000.

RAMOS, Arthur. As culturas negras no novo mundo. 3.ed. São Paulo: Brasiliana, 1979.

RODRIGUES, Nina. Os Africanos no Brasil. São Paulo; Brasília: Nacional; EdUnB, 1988.

O animismo fetichista dos negros baianos. Rio de Janeiro: Fundação Biblioteca da Nacional, Editora UFRJ, 2006.

SCHECHNER, Richard. A rua é o palco. Performance e antropologia de Richard Schechner. Rio de Janeiro: Editora Mauad X, 2012: 155-198.

SILVA, Vagner Gonçalves da. Religião e relações raciais na formação da antropologia no Brasil. In: PINHO, Osmundo Araújo. SANSONE, Lívio (orgs). Raça: novas perspectivas antropológicas. Salvador: ABA e EDUFMA, 2008: 285-313. 